\title{
SYNOPTIC ATMOSPHERIC PATTERNS CONTROLLING THE NORTH-WEST AFRICAN OCEANOGRAPHIC VARIABILITY
}

\author{
Aïssa Benazzouz* \\ Institut Supérieur d'Etudes Maritimes, El Jadida, Casablanca-Morocco; \\ Marine geosciences and sol sciences Laboratory,Associated Unit URAC, Faculty of sciences, \\ University Chouaib Doukkali, B.P., El Jadida, Morocco; \\ Faculté des Sciences Ben M'Sik Polymer Physics and Critical Phenomenon Laboratory, Casablanca- \\ Morocco

\section{Khalid EL Khalidi} \\ Marine geosciences and sol sciences Laboratory,Associated Unit URAC , Faculty of sciences, \\ University Chouaib Doukkali, B.P., El Jadida, Morocco; Geosciences laboratory, Faculty of Sciences, \\ University Ibn Tofail, BP, Kenitra, Morocco \\ Hassan Mabchour \\ Institut Supérieur d'Etudes Maritimes, El Jadida, Casablanca-Morocco; \\ Laboratory Mechanical Control and Characterization of Materials and Structures, BP, ENSEM, \\ Casablanca, Morocco \\ Khalid EL Had \\ Institut Supérieur d'Etudes Maritimes, El Jadida, Casablanca-Morocco

\section{Soumia Mordane} \\ Faculté des Sciences Ben M'Sik Polymer Physics and Critical Phenomenon Laboratory, Casablanca- \\ Morocco

\section{Bendahhou Zourarah} \\ Marine geosciences and sol sciences Laboratory,Associated Unit URAC , Faculty of sciences, \\ University Chouaib Doukkali, B.P., El Jadida, Morocco \\ Naoki Tojo \\ JICA, Japan \\ Hervé Demarcq \\ MARBEC Res. Unit 248, IRD, IFREMER, CNRS - Université De Montpellier, French
}

*Corresponding Author 
Synoptic atmospheric patterns controlling the North-West African oceanographic variability

\begin{abstract}
The purpose of this paper is to describe the synoptic atmospheric conditions that control the oceanographic variability in the Canary Current Ecosystem (CCE) and how the coastal upwelling process reacts to the atmospheric forcing, recognized as highly variable. We also show that climate indices such as Sea Level Pressure (SLP) and North Atlantic Oscillation (NAO) can both be used to predict the upwelling process.

The seasonal and interannual variations of of the Northwest African upwelling between $21^{\circ} \mathrm{N}$ and $36^{\circ} \mathrm{N}$ (the African part of the CCE) and its response to large-scale atmospheric variations such as NAO and SLP is studied for the three decades spanning the period 1982-2011 using remote sensing sea surface temperature (SST) and NCEP/NCAR climatic data.

To describe and analyze the results, the spatial scenarios of the synoptic and global climatology were investigated and a variety of analysis methods have been applied.

It is demonstrated that the intensity of the Azores High over the Eastern Atlantic Ocean determines the strength of the southward upwelling favorable wind especially during the summer to winter transition, better than the NAO index. Furthermore, The estimated cross-correlation between the NAO and the coastal upwelling index derived from SST is weak, due to a lack of correlation.

However, the NAO is more adequate than the SLP alone to explain upwelling extreme events, rather than the long-term (5-6 years) upwelling variability observed.

Key words: Atmosphere, ocean, North Atlantic oscillation, sea level pressure, sea surface temperature.

Cite this Article: Aïssa Benazzouz, Khalid EL Khalidi, Hassan Mabchour, Khalid EL Had, Soumia Mordane, Bendahhou Zourarah, Naoki Tojo and Hervé Demarcq, Synoptic atmospheric patterns controlling the North-West African oceanographic variability, International Journal of Advanced Research in Engineering and Technology, 11(12), 2020, pp. 825-844.

http://iaeme.com/Home/issue/IJARET?Volume $=11 \&$ Issue $=12$
\end{abstract}

\title{
1. INTRODUCTION
}

The Canary Current Ecosystem (CCE), situated in the northern subtropics along the North-west Africa (NWA) $\left(11-35^{\circ} \mathrm{N}\right.$, Fig.1) is an important socio-economic, oceanographic and climatological region. The Canary Current is the eastern, southward flowing component of the North Atlantic Subtropical Gyre. The CCUE is one of the four major coastal upwelling regions of the world (Benguela, Humboldt and California), also named Eastern Boundary Upwelling Ecosystems (EBUEs) (Hagen et al. 2001; Thiel et al. 2007; Pérez-Brunius et al. 2007).

The coastal upwelling is driven by alongshore winds and produces a net cross-shore transport (Ekman, 1956, Pedlosky, 1978), brings cooler and nutrient-rich water from the subsurface (50 to $150 \mathrm{~m}$ ) into the upper part of the euphotic layer, leading to an intense primary production. 
Aïssa Benazzouz, Khalid EL Khalidi, Hassan Mabchour, Khalid EL Had, Soumia Mordane, Bendahhou Zourarah, Naoki Tojo and Hervé Demarcq

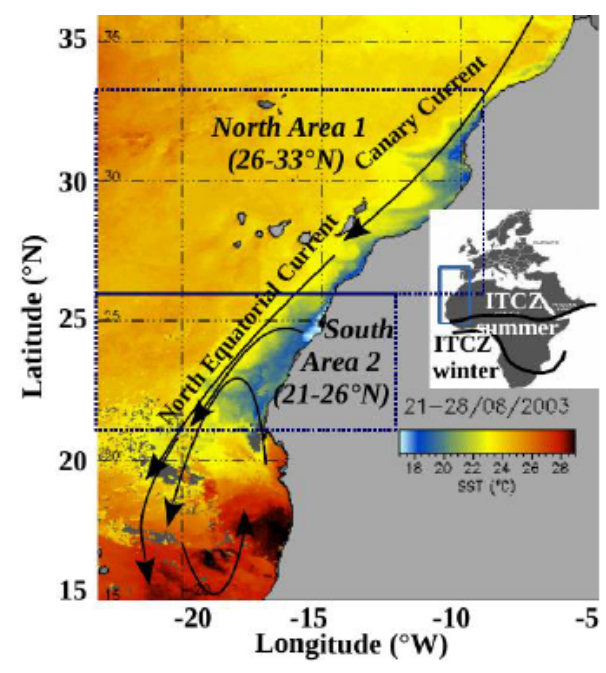

Figure 1 Remote sensing sea surface temperature (NOAA/AVHRR) highlighting the cold coastal upwelling water with zoning of the region under study into two subareas area 1 (northern area) with seasonal upwelling and area 2 (southern area) with permanent upwelling superimposed with some of the major ocean currents (Adapted from Benazzouz et al. 2014a)

The upwelling favorable-winds off NWA are associated with the anticyclonic motion of the lower atmosphere around the Azores High in the North Atlantic Ocean (Fig. 2). The Azores High is part of the Hadley-Circulation and is latitudinaly moving between about $25^{\circ} \mathrm{N}$ in late winter and $35^{\circ} \mathrm{N}$ in late summer and drives both the intensity and the latitudinal extension of the north-easterly winds off NWA. Several studies have explored the seasonal variability in both wind forcing and coastal ocean response (Wooster et al. 1976; Speth et al. 1978, 1983; Nykjaer and Van Camp 1994; Benazzouz et al. 2014). The shorter-lived ocean and atmospheric dynamics phenomenas are absent from the averaged time series and only the synoptic variability remains. In general, mesoscale $(10-20 \mathrm{~km})$ atmospheric processes tend to be fast (few days) while basin-scale and large-scale processes tend to be slow (season). As pointed out by Benazzouz et al (2014b), the surface winds and upper ocean are tightly linked to these short scales, but such a low-pass filter leads to a poor correlation between surface winds and SST. However, the correlation remains high between ocean and atmosphere, with a typicallag of 1 month(Nykjaer and VanCamp 1994) to 3 months (Benazzouz et al. 2014a,b).
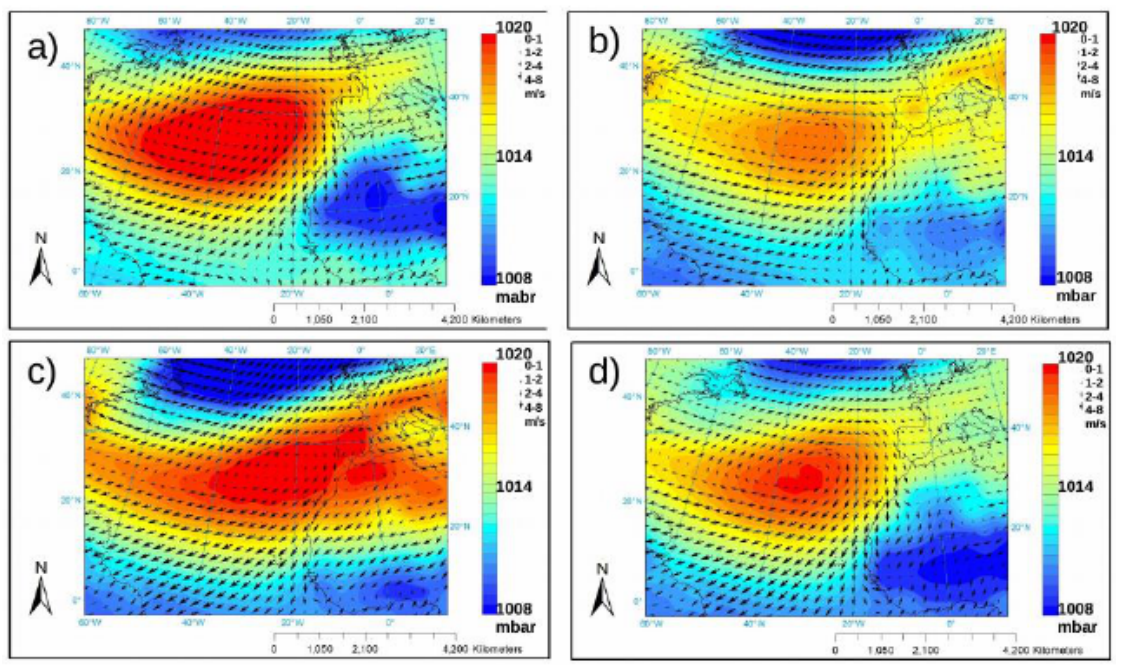

Figure 2 Seasonal maps showing the surface atmospheric pressure field (in mbar) associated with the corresponding seasonal wind field: (a) Summer, (b) Autumn, (c) Winter and (d) Spring 
The large-scale climate dynamic has attracted a lot of attention because it modulates local and global climate (Hurrell 1995), specially at middle and high latitudes in the North Atlantic Ocean (Cayan 1992). During the last ten years, the mechanisms that drive the NAO variability at intraseasonal time scales have been a major concern in the atmospheric research field in the region, from direct observation as from modeling and theoretical approaches (Feldstein 2003; Benedict et al. 2004; Franzke et al. 2004; Luo et al. 2007a,b; Luo et al. 2010a,b, 2011). It remains that the underlying mechanisms are questionable and misunderstood.

The NAO is an important dipole climatic mode (Rogers 1997) defined as the difference of the sea level air pressure between the subtropical anticyclone near the Azores and the sub-polar low pressure system near Iceland (Walker 1924; Walker and Bliss 1932). It is characterized by an important cyclical oscillation of air pressure and therefore in the strength and position of the Atlantic westerly winds (Walker 1924). Trade wind intensity, as the dominant low-level parameter of the atmospheric dynamics in the North Atlantic throughout the year, with a winter maximum (Hurrell et al. 2003), explains more than a third of the sea level pressure variability at a monthly scale (Ottersen et al. 2001). However, It plays a role of great importance in modifying interannual variability of the upwelling process during the other transitional seasons (autumn-spring).

At interannual time scales, observational results demonstrate that wind anomalies might be able to force the ocean via heat fluxes and surface mixing (Wallace et al. 1990; Zorita et al. 1992). The NAO variability induces changes in sea surface temperature (SST) and subsequent fluctuations modify the intensity of the northeast trade wind system and cause inter annually occurring changes in coastal upwelling patterns off Northwest Africa. Consequently, changes in the NAO appear to be determinant on marine ecosystem ecology, specially on fisheries (Planque and Frédou 1999; Brander and Mohn 2004; MacKenzie and Koster 2004).

During positive NAO phases (NAO+) an intensification of the trade northeast winds and the upwelling intensity is observed. The inverse situation occurs during negative NAO phases (NAO-).

The fluctuations in the upwelling extension are controlled by the predominant trade winds that are largely determined by the NAO which is itself controlled by Subtropical Atlantic Gyre (Van Camp et al. 1991; Nykjaer and Van Camp 1994). The NAO can explain 50\% of SST annual variability in the Atlantic area (Helmke 2003) and is also significantly correlated to the meridional wind stress component (Visbeck et al. 1998).

For this study we have analyzed upwelling index derived from remotely sensed SST and wind data to clear the seasonal and interannual variations of the upwelling fluctuation in response to the atmospheric forcing. However, information on the longer-term variability of SST upwelling index and its connection with the large-scale atmospheric forcing is still limited and poorly investigated (Ginzburg et al. 2004; Oguz 2005; Kazmin and Zatsepin 2007).

The objective was furthermore to establish a link between large-scale atmospheric forcing (surface wind, NAO index and sea level pressure) and the meso-scale NWA upwelling response as depicted an SST-based coastal upwelling index (CUISST).

This paper is organized as follows: Section 2 presents the data collection used for this study. Section 3 presents the statistical analysis of mainly four time series of NAO indices, SLP, Wind and CUISST as well as a diagnostic study of the scenarios states of the NAO, including a spectral analysis. Section 4 deals with the main statistical results and discussions.

Conclusions are given in section 5 . 
Aïssa Benazzouz, Khalid EL Khalidi, Hassan Mabchour, Khalid EL Had, Soumia Mordane, Bendahhou Zourarah, Naoki Tojo and Hervé Demarcq

\section{DATA SETS}

\subsection{Surface wind}

The data used for the zonal and meridional wind components comes from two sources:

- NCEP/NCAR Wind: data were retrieved from the National Centers for Environmental Prediction / National Center for Atmospheric Research (NCEP/NCAR). Reanalysis data are monthly available from 1948 onwards covering the following domain: $15-45^{\circ} \mathrm{N}$ and $70-5^{\circ} \mathrm{E}$ at a spatial resolution of 2.5 $\times 2.5^{\circ}$ (Kalnay et al. 1996).

- CCMP wind: The Cross-Calibrated, Multi-Platform Ocean Surface Wind Velocity (CCMP) funded under the NASA Earth Science Enterprise, is an ocean surface wind data set outcome from variational analysis method (Atlas et al. 2009) of several available scatterometers wind data sets (SeaWinds on QuikSCAT and ADEOS-II, NSCAT, etc.) and microwave sensors (AMSRE on Aqua, TRMM on TMI and $\mathrm{SSM} / \mathrm{I}$ and SSMIS on DMSP platforms). This product is a consistent data record of high resolution $(25 \mathrm{~km})$ ocean surface winds and long chronological time series spanning the period from July 1987 to December 2011.

The NCEP wind is used to represent the wind field distribution superimposed to SLP while the CCMP wind is used for statistical analyses.

\subsection{Atmospheric sea-level pressure (SLP)}

We use Atmospheric Sea Level Pressure (SLP) data also from the NCEP which provides atmospheric reanalysis from 1948 to the present day (Kalnay et al. 1996). The coverage of the NCEP reanalysis is global on a $2.5^{\circ} \times 2.5^{\circ}$ grid and a 6 hour temporal sampling and 17 pressure levels. In this paper, we used monthly and seasonaly averaged surface pressure fields from 1982 to 2011. We also used the SLP times series from the SLP Ponta Delgada (Azores) station.

\subsection{North Atlantic Oscillation (NAO)}

The North Atlantic Oscillation index (NAO), defined as the normalized SLP difference from Ponta Delgada (Azores) and Reykjavik (Iceland) meteorological stations (Hurrel 1995) is used. The monthly NAO index series were taken from Hurrel $(1995,1996)$ at theNCEP/NCAR Reanalysis Project.

\subsection{SST Coastal Upwelling index (CUIssT)}

A 30 years sea surface temperature (SST) data sets time series from the AVHRR (Advanced Very High Resolution Radiometer) version 5.2 day time for the time period September 1982 to December 2011 were used.

The thermal difference between inshore and offshore SST is used to compute the coastal upwelling index, here after noted CUIsst. as defined in Benazzouz et al. 2014..

Different thermal upwelling indices were used by several authors, derived either from insitu measurements (Wooster et al. 1976; Speth et al. 1978; Speth and Köhne 1983; Mittelstaedt 1983) or satellite data (Mittelstaedt 1991; Van Camp et al. 1991; Nykjær and Van Camp 1994; Demarcq and Faure 2000; Santos et al. 2005; Lathurilère et al. 2008; Marcello et al. 2011; Santos et al. 2011; Benazzouz et al. 2014a, 2014b) in order to estimate the latitudinal and temporal variability of the intensity of the upwelling. 


\section{METHODS}

A time series of the SST-based coastal upwelling index is computed, following the methodology defined in Benazzouz et al. (2014a) from 1981 to 2011 along the Moroccan Atlantic coast, from $12^{\circ} \mathrm{N}$ to $36^{\circ} \mathrm{N}$.

To carry out our analysis, the Moroccan area was subdivided into two sub-regions based on the seasonal upwelling regime: the Northern region (Area $1,26-33^{\circ} \mathrm{N}$ ) where the upwelling is seasonal and occurs in summer and on the southern region (Area 2, 21-26 ${ }^{\circ} \mathrm{N}$ ) where the upwelling is almost permanent (Vamp Camp and Nykjaer 1994; Benazzouz et al 2014a,b; Benazzouz et al. 2015).

Sea level pressures at sea surface are extracted at the center of the Azores High, from $27^{\circ} \mathrm{N}$ to $35^{\circ} \mathrm{N}$ and $330^{\circ} \mathrm{W}$ to $342.5^{\circ} \mathrm{W}$. The North Atlantic Oscillation index (NAO) has been used for the same period (1981-2011). Temporal autocorrelation of monthly average of the indices was examined at $\alpha=0.05$ level.

Monthly time series (1988 - 2011) of the north-south CCMP wind (U and V components) were used as direct drivers of the upwellingfor each sub-region.

Linear correlations were examined using the Person's correlation coefficient using t-tests between wind intensity, synoptic and global indices, and the thermal upwelling index from 1982 to 2011. The analysis results were presented in the form of correlation matrix for each season.

The composite analysis is taken as a complementary asset of the correlation analysis, it is a flexible method used in climatology to highlight the existence of non-linear relationships between variables.

The analysis of the sample cross correlation functions, allowed the investigation of the memory structure and the statistical relationships between the meteorological variables and the CUISST .

While spectral estimates of climatological time series can be used to study predictability, if clear periodicities exist, it can then be extrapolated into the future and give insight into the dynamics of the system.

We used the smoothed periodogram (Venables and Ripley 2002) which uses the Fast Fourier transform.

Indeed, all the environmental indicators, thermal upwelling indices and the two CCMP wind components zonal (U) and meridional (V) were considered according to the spatial division mentioned before.

On a seasonal basis, three major seasons were considered, winter (December "year before", January, February and March "year after"), summer (June, July and August) and autumn (September, October and November). This last season has received a lot of attention as it is a transitional season during which the atmospheric forcing begins to manifest strongly the entire ecosystem changes and causes the seasonal migration of pronounced upwelling, which follows the northward shift of the north-east trade in late spring and back in winter.

\section{RESULTS}

\subsection{Seasonality of the SLP and the Associated Wind Field}

The Fig. 2 of the atmospheric pressure field and the associated wind field clearly shows that the spatial and temporal distribution of the wind is determined by the seasonality and displacement of the core of the high atmospheric pressure system.

Indeed, the seasonality of the pressure field is characterized by two important elements: first, by the intensity of the center of action (Azores High) pressure system, secondly, by the spatial location of the core and its area of influence. During summer (Fig.2a), the center of 
Aïssa Benazzouz, Khalid EL Khalidi, Hassan Mabchour, Khalid EL Had, Soumia Mordane, Bendahhou Zourarah, Naoki Tojo and Hervé Demarcq

action of the high pressure system is positioned at $\sim 35^{\circ} \mathrm{N}$, with a very limited area of influence translated by a stronger wind intensity interesting both the Morocco northern area and the Iberian Peninsula.

During winter (Fig.2c), the pressure field is much more intense with a strong center of action, very diffuse and localized at $\sim 32^{\circ} \mathrm{N}$. The area of influence shows a much larger zonal extension affecting NWA and Europe (with very pronounced Northesatward extension). The resulting wind field is stronger in the Senegal-Mauritanian zone, and in southern Morocco. We can thus remember that the seasonal southward migration of the high atmospheric pressure core (in the Azores) from summer to winter from $35^{\circ} \mathrm{N}$ to $32{ }^{\circ} \mathrm{N}$ (Davis et al. 1997) strongly forces the southward trade winds shift and therefore the upwelling favorable wind. Consequently, the intensity of the atmospheric pressure field determines the intensity of the wind field and hence, the intensity of the upwelling. The shape and distribution of the pressure field in Autumn is almost identical to that of the winter season, except that the intensity of the pressure field is of less importance than the winter season. This will make us dare to say that the Autumn season can be considered as a small atmospheric winter season.

The analysis of the seasonality of the pressure field reveals that the transition between summer and winter will be decisive for the intensity and distribution of the wind field. The longer the transition from the summer situation to the winter situation, the more the winter pressure field will be normal and vice versa. And any transient anomaly could potentially disturb the wind field and consequently the dynamics and the seasonality of the coastal upwelling.

\subsection{Interannual Variability}

We conducted our time series analysis in two different ways. Firstly, we used hovmöllers diagrams of the interannual variability of the thermal upwelling index for each season (summer, autumn and winter). In the second order, we used plots of the interannual variability by comparing all the variables together: NAO, SLP, CCMP wind (U, V) and the thermal upwelling index for each of the sub-areas (central and south).

In all seasons, the thermal upwelling index (CUISST) is higher in the south than in the center (Fig.3, 4 and 5). During the last years, the difference in summer becomes very distinctive. On the other hand, the difference between north and center becomes low in winter.

The whole time series is characterized by considerable interannual variability with periods of strong upwelling intensity (1982, 1984, 1991, 1993, 1996, 1998, 1999, 2002 and 2005) and period of weak upwelling activity $(1983,1987,1989,1990,1994,1995,1997,1998,2001$, 2005, 2006 and 2009). Nevertheless, only a few years present clear anomalies for the whole system, as 1995-1997 or 2008-2009, where the north-south propagation of the high upwelling intensity is remarkable. On the other hand, several exceptional upwelling seasons were found to occur partially related to dome part of the system. For example, a strong decrease of the upwelling was observed from late 1995 to 1998 in the Northern part of the system (Fig.3a, b and c), related to an exceptional relaxation of the trade winds (Fig.4). These strong anomalies have been associated to the collapse of the sardine stock between 1996 and 1997 (Machu et al. 2009) in the region. On the contrary, some years are associated to strong upwelling seasons only in the southern part of the system, as in 1986, 1996, 1999, 2005, 2009 and 2011. 
In general, the interannual variability of the wind and CUISST exhibits similar patterns: high wind intensity coincides with intense CUISST (1999, 2001, 2002, 2007 and 2008); and vice versa, low wind intensity coincides with relaxed CUISST (1995-1998).

The hovmöllers diagrams (Fig.3a, b and c) show a high seasonal and interannual spatial variability of the upwelling intensity. During the summer season (Fig.3a), the upwelling is intense in both Moroccan sub-regions. From summer to winter, the seasonal maximum shifts from summer in the northern zone of Morocco to a permanent situation in the south, then to a winter-Autumn situation (Fig.3c) at the extreme southern Morocco. The seasonality of the seasonal maximum from north to south of our study area can be explained by the seasonal shift of the trade wind and the southward displacement of the center of action of Azores High in the North Atlantic.

\section{a)}
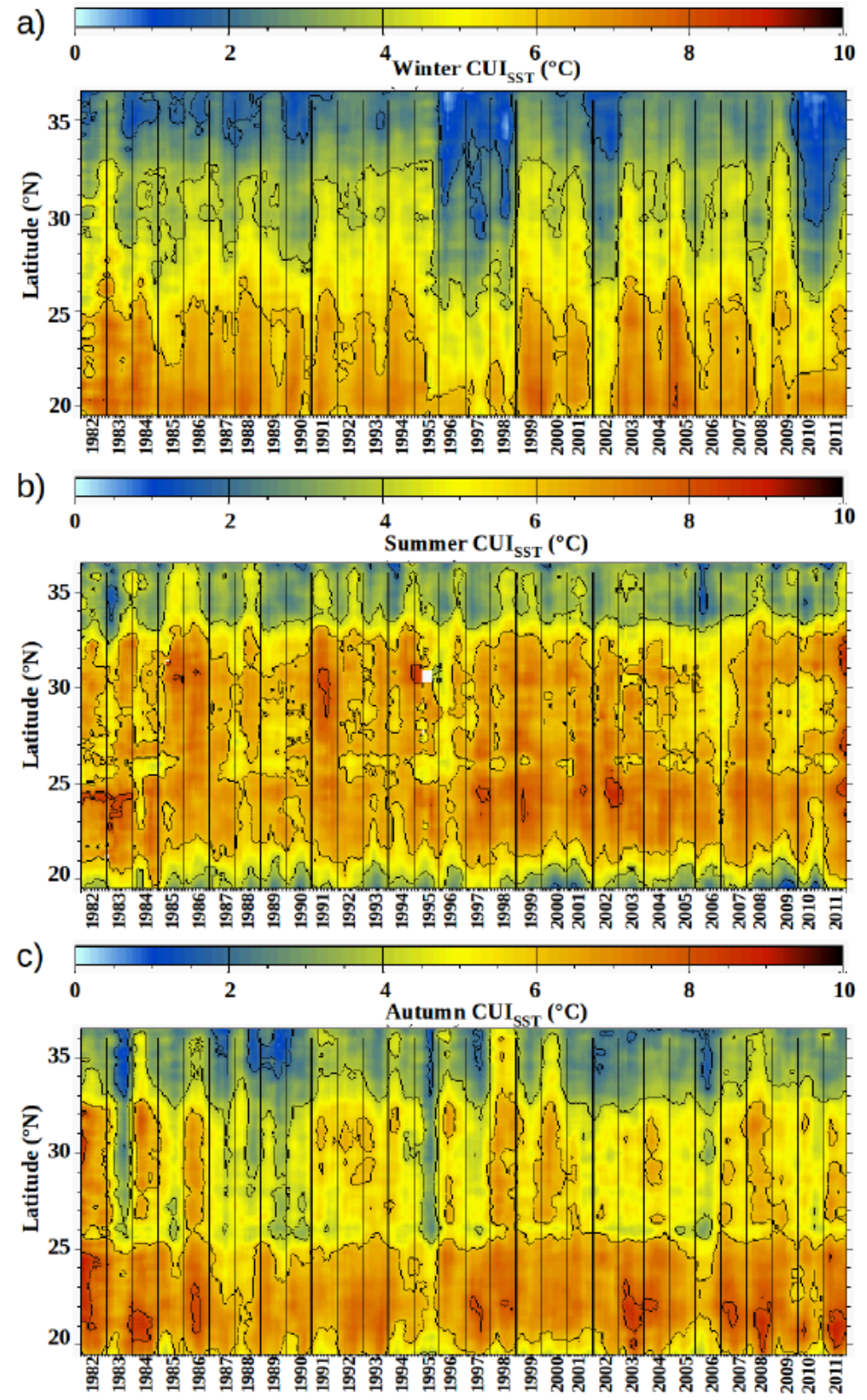

Figure 3 Space-times Hovmöllers plots of the (a) winter, (b) summer and (c ) autumn interannual variability of the CUIssT from 1982 to 2011 ; the values 2, 4, 6 and 8 of the CUISST are isocountoured. 


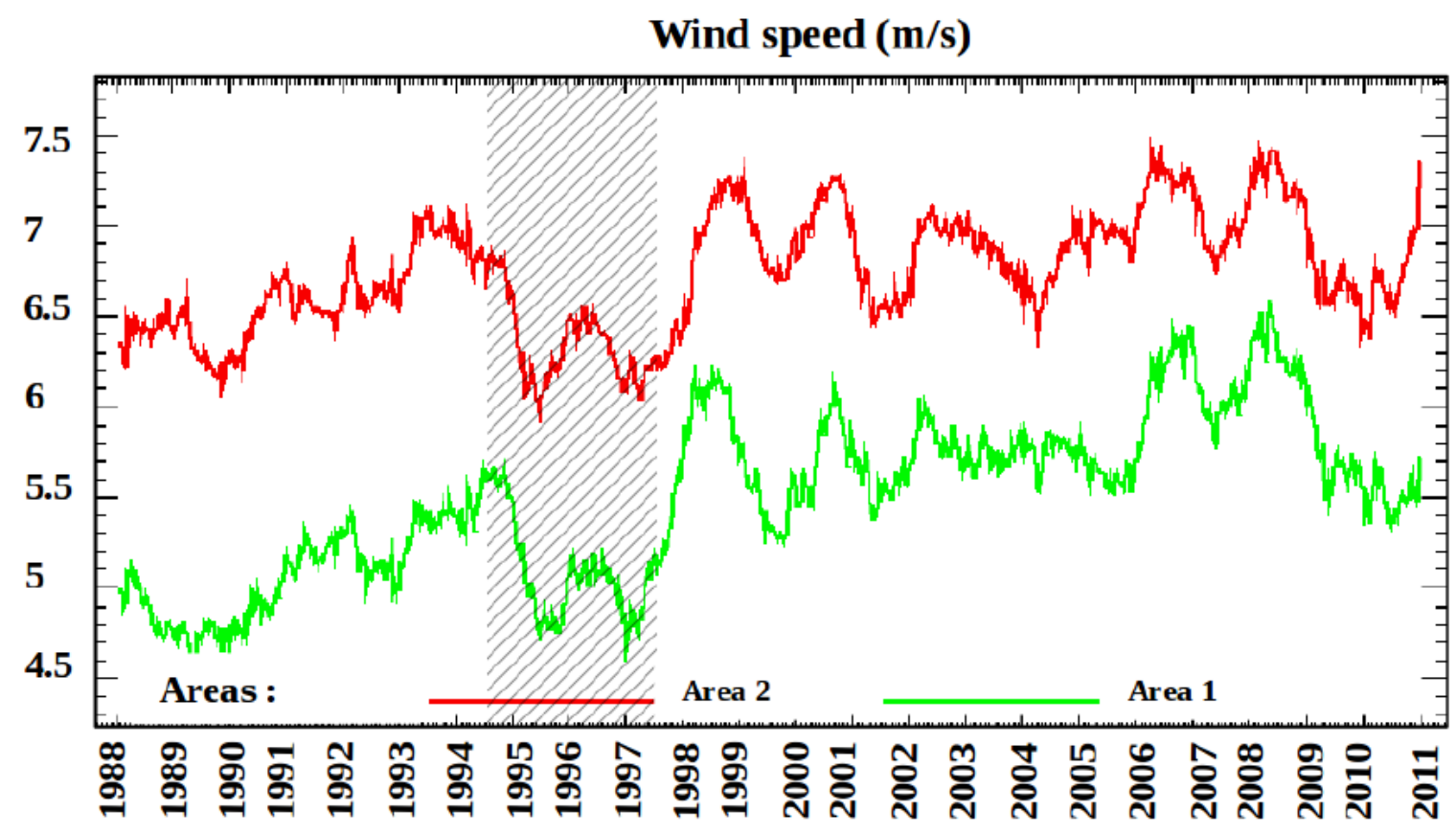

Figure 4 Interannual variability of the wind intensity along the two areas: northern area (area 1) green curve and southern (area 2) red curve; The anomalous period (1995-1997) is marked by the hatched bar.

The time series shows that the SLP and the NAO, follow the general variability of the upwelling index (Fig.5). On the other hand, during summer and autumn, the thermal upwelling index in both the central and the southern zone is intensified after the anomalous situation observed during 1995-1998 (Figures 3a, b and c). During this anomalous period, Moroccan coastal upwelling displays its lowest winter intensities of the whole time series of study (19822011). This signal was initially observed in the Autumn of 1995 when the intensity of the CUISST was very week, specially in central Morocco (Fig.3c) during this season (Benazzouz et al., 2014a). This can be explained in two different ways:

- First, the atmospheric pressure in the Azores High during the winter seasons from 1995 to 1997 (Fig.5) was the lowest throughout the studied period ( $<1018$ mbar). Consequently, the presence of a very negative NAO phase (NAO-) during the winter of 1995, 1996 and 1997 may explain the Autumn in upwelling activity during this period of strong anomaly.

- Secondly, if we look at the NAO (Fig.5) and the average atmospheric pressure field associated with the wind field during this period with a special attention to the 1997 winter season, we noticed that there is a change of NAO regime which passes from a positive phase to a negative phase. This later is expressed as a very low pressure at the core of the system and with a much smaller area of influence and very sparse wind field (Fig.6a). This further justifies the causal relationship between the synoptic dynamics in term of SLP, the atmospheric response in terms of the wind field and finally the thermal oceanic response via the cold coastal resurgences computed by the CUISST. 


\section{Summer}


\section{Autumn}
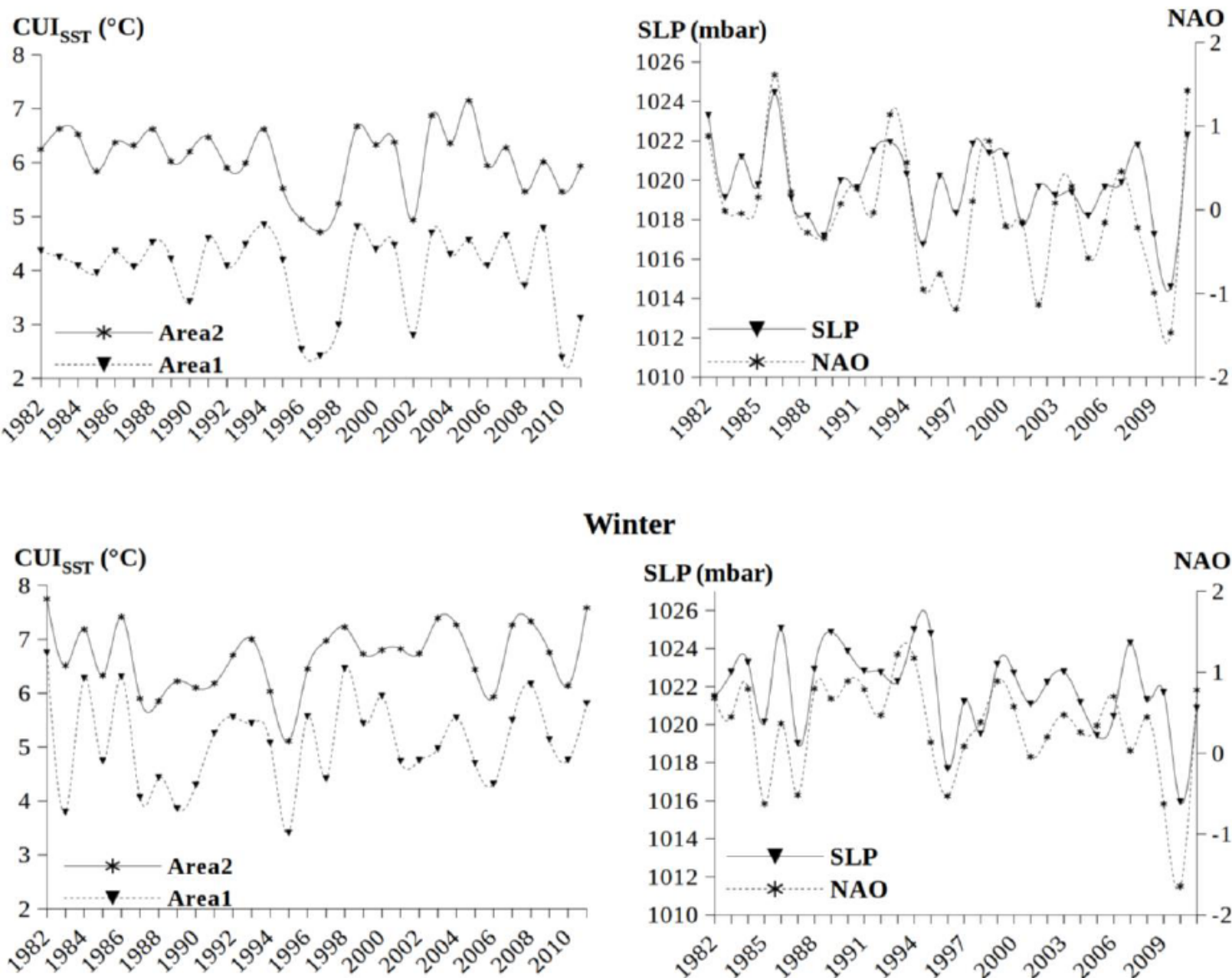

\section{Winter}



Figure 5 Time series of CUISst for each zone, South (area 2) and North (area 1) of Morocco (left columns); NAO index, and SLP (right column) for each seasons: summer (top), autumn (middle) and winter (down). 
Aïssa Benazzouz, Khalid EL Khalidi, Hassan Mabchour, Khalid EL Had, Soumia Mordane, Bendahhou Zourarah, Naoki Tojo and Hervé Demarcq
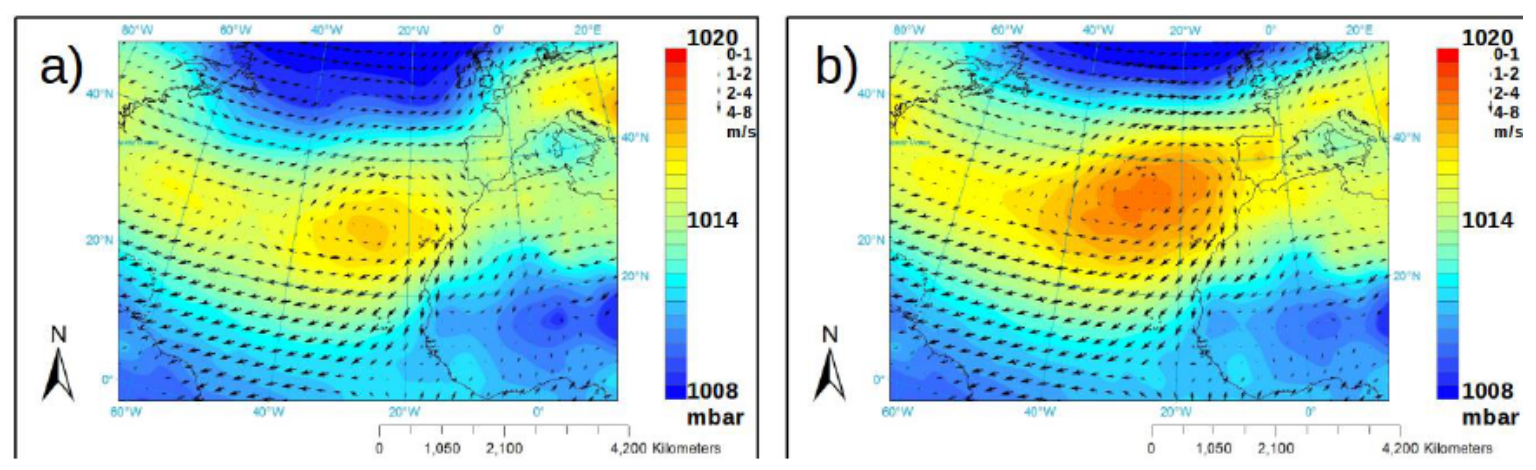

Figure 6 Ocean surface atmospheric pressure and the associated wind field: (a) winter 1997, (b) mean winter field (1995, 1996 and 1997)

In addition very wide variations were observed of the time history of occurrence of the NAO regimes with a general decrease in its average intensity after 1995 followed by values close to zero in 1996-1997 and extreme negative values in 2010-2011. The highest index occurred in 1993 and 1994 (Fig. 5c and 7) was also reported by Hurrell (1995) and Santos et al. (2005). This downward trend observed in the NAO is not reflected in the upwelling index, however, all the extreme events observed in 1983, 1994, 1996-1997, 1999 and 2010-2011 are visible in the CUISST series (Gray Bars in Fig.7) for the separate areas.

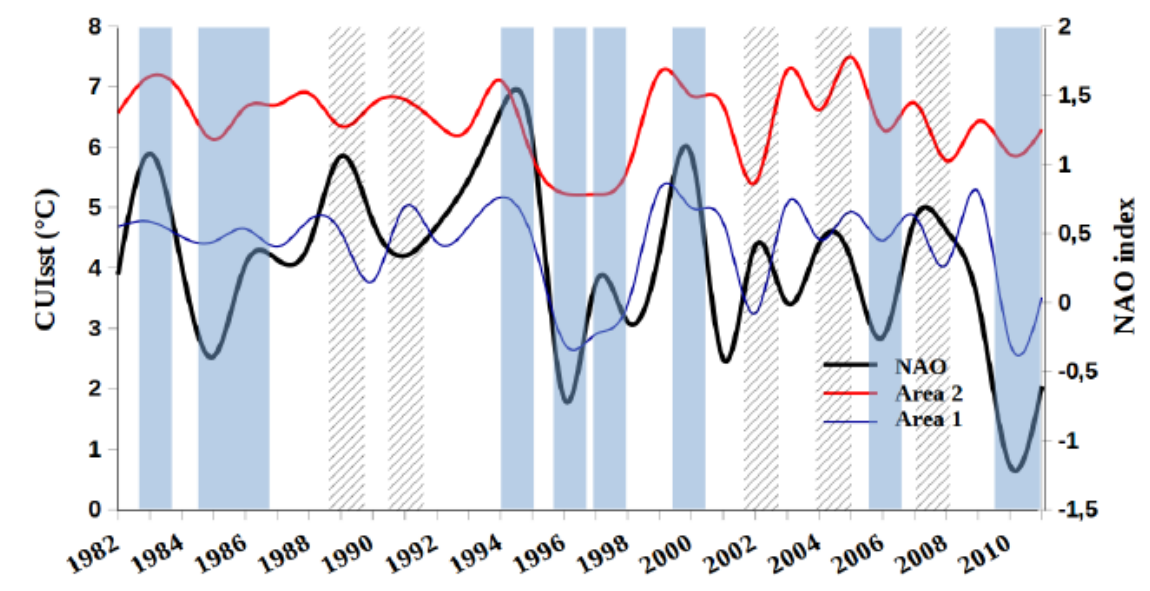

Figure 7 Comparison of the variability of the CUISST in southern (area 2) and northern (area 1) Morocco (colored lines) with the North Atlantic Oscillation index (black line) from 1982 to 2011.

Grey bars represent positive response to NAO and hatched bars rather negative response

Last but not least, this result shows that the NAO can potentially plays a very important role in the observed extreme events of upwelling rather in the long-term variability of upwelling. On the other hand, a similar number of NAO events are negatively reflected by our index (Hatched Bars in Fig.7) as is the case for the years 1984-85, 1988-1989, 1992, 2001-2002, 2004 and 2007.

In order to study the effect of climate indices on the wind field spatial structure, we did not attempt to take into account only the intensity of the center of action, but also, we took into account the area of influence and the location of the high-pressure core. Therefore, we constructed a spatialized representation of the anticyclonic pressure core based on composite analysis (Fig. 8 and 9).

In the extreme season of statistical relationships among the variables, the spatial scenarios of the synoptic and global climatology were investigated. The five extreme years of upwelling intensity were selected (Table 1). Average sea level pressure at surface and wind vector over 
the studied region were compared between these lower and upper extreme years for each subregion and their differences were computed, in order to see how the pressure field acts on the wind field distribution for each of the Moroccan sub-areas. Furthermore, spatial scenarios of synoptic and global climatology were investigated based on the spatial distribution of the pressure field and the associated wind field anomaly.

Table 1 Extremely weak and strong years in terms of upwelling activity for both northern $\left(26-33^{\circ} \mathrm{N}\right)$ and southern $\left(21-26^{\circ} \mathrm{N}\right)$ areas of Morocco

\begin{tabular}{ccc}
\hline & \multicolumn{1}{c}{ Extremely strong years } & Extremely weak years \\
\hline $26-33^{\circ} \mathrm{N}$ & $1982,1984,1986,1998,2004$ & $1995,1996,1997,1999,2001$ \\
$21-26^{\circ} \mathrm{N}$ & $1981,1982,1984,1986,2008$ & $1995,1996,1997,1999,2001$ \\
\hline
\end{tabular}

The composite analysis of the extreme years (positive and negative anomalies) of the upwelling activity for the northern zone (area 1) (Fig.8) and the southern zone (area 2) (Fig.9), reveals that in the area 1 , the intensification of the high pressure system and the associated wind is very distinct over the entire zone.

The composite of observed mean sea level pressure anomalies reveals a well-known NAO pressure dipole with increased SLP over the northern part and decreased SLP over the southern part of the domain, resulting in a strong meridional SLP gradient around $26^{\circ} \mathrm{N}$. While, the southward migration of the high pressure system, shows that the SLP at the Azores loses slightly of its intensity and its area of influence. A bipolar structure of the wind field at the Moroccan Atlantic coast is printed by the high-pressure field at the Azores. Indeed, the resulting wind is parallel to the coast and favorable for upwelling along the entire study area despite the difference noted in terms of wind intensity between sub-areas (north and south).
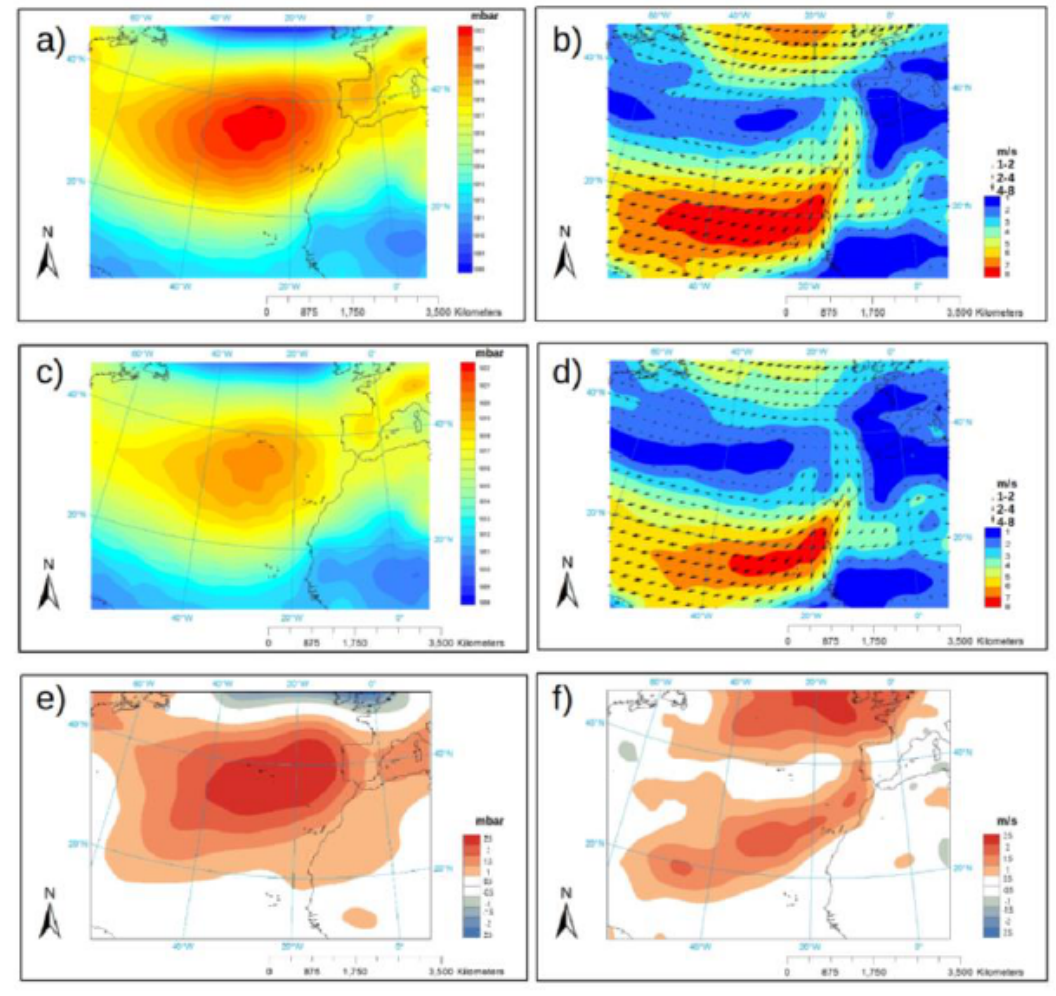

Figure 8 Averaged (a) SLP and (b) associated wind field of the strongest upwelling index; (c) SLP and (d) associated wind field of the weakest upwelling index; The significante composite difference $(\mathrm{P}<0.05)$ between strongest and lowest scenario for (e) SLP and (f) associated wind for the Moroccan northern zone (area1) 
Aïssa Benazzouz, Khalid EL Khalidi, Hassan Mabchour, Khalid EL Had, Soumia Mordane, Bendahhou Zourarah, Naoki Tojo and Hervé Demarcq
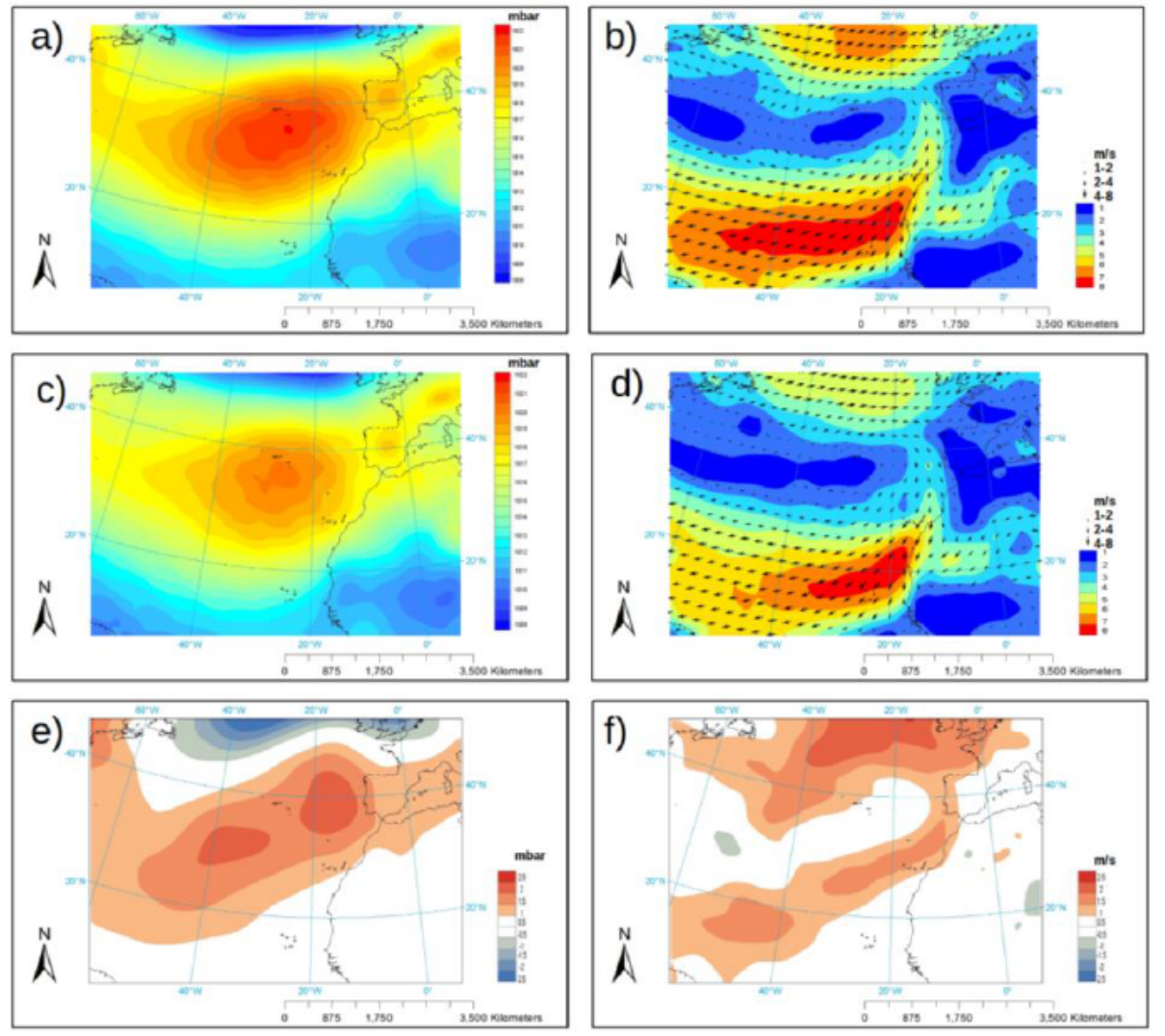

Figure 9 Averaged (a) SLP and (b) associated wind field of the strongest upwelling index; (c) SLP and (d) associated wind field of the weakest upwelling index; The significante composite difference $(\mathrm{P}<0.05)$ between strongest and lowest scenario for (e) SLP and (f) associated wind for the Moroccan southern area (area2)

\subsection{Statistical correlations}

Seasonal statistical correlations were performed to investigate the association degree between synoptic climate indicators and oceanic variables.

Seasonal correlations matrix were calculated for Summer, Autumn and Winter for NAO and SLP and for each area (northern and southern Morocco) for CUISST, and CCMP (U and V) (Tables, 2).

Table 2: Correlation matrix of estimated linear association between the CUISST, U, V, NAO and SLP for each sub-area (Center and South) for (from up to down) the summer, autumn and winter season. The symbols $(* * *)$ indicate statistically significance correlation $(\mathrm{P}<0.05)$ and $(-)$ no significance relationship.

\begin{tabular}{|l|llllllll|}
\cline { 2 - 8 } Summer & CUI(South) & CUI(North) & NAO & SLP & V(South) & V(North) & U(South) & U(North) \\
\hline CUI(South) & 1,00 & $* * *$ & --- & --- & -- & -- & --- & -- \\
CUI(North) & 0,71 & 1.00 & -- & $* * *$ & $* * *$ & $* * *$ & --- & -- \\
NAO & $-0,210$ & $-0,11$ & 1.00 & --- & --- & --- & -- & -- \\
SLP & 0,17 & 0,43 & 0,04 & 1.00 & -- & -- & --- & -- \\
V(South) & $-0,09$ & $-0,47$ & $-0,21$ & $-0,39$ & 1.00 & $* * *$ & $* * *$ & -- \\
V(North) & $-0,11$ & $-0,49$ & $-0,19$ & $-0,41$ & 0,95 & 1,00 & $* * *$ & -- \\
U(South) & $-0,02$ & 0,17 & 0,28 & 0,10 & $-0,68$ & $-0,60$ & 1.00 & $* * *$ \\
U(North) & 0,11 & 0,00 & 0,14 & $-0,10$ & $-0,28$ & $-0,11$ & 0,77 & 1.00 \\
\hline
\end{tabular}


Synoptic atmospheric patterns controlling the North-West African oceanographic variability

\begin{tabular}{|l|llllllll|}
\cline { 2 - 8 } \multicolumn{1}{c}{ Autumn } & CUI(South) & CUI(North) NAO & SLP & V(South) & V(North) & U(South) & U(North) \\
\hline CUI(South) & 1,00 & $* * *$ & --- & --- & $* * *$ & $* * *$ & --- & --- \\
CUI(North) & 0,79 & 1,00 & --- & --- & $* * *$ & $* * *$ & --- & $* *$ \\
NAO & 0,25 & 0,06 & 1,00 & $* * *$ & --- & --- & --- & --- \\
SLP & 0,13 & 0,08 & 0,42 & 1,00 & --- & --- & --- & --- \\
V(South) & $-0,63$ & $-0,73$ & 0,18 & 0,21 & 1,00 & $* * *$ & --- & --- \\
V(North) & $-0,63$ & $-0,83$ & 0,18 & 0,06 & 0,88 & 1,00 & $* *$ & $* *$ \\
U(South) & 0,03 & $-0,31$ & 0,30 & $-0,12$ & 0,21 & 0,50 & 1,00 & $* * *$ \\
U(North) & $-0,17$ & $-0,48$ & 0,03 & $-0,18$ & 0,28 & 0,65 & 0,79 & 1,00 \\
\hline
\end{tabular}

\begin{tabular}{|l|llllllll||}
\cline { 2 - 8 } \multicolumn{1}{l|}{ Winter } & CUI(South) & CUI(North) & NAO & SLP & V(South) & V(North) & U(South) & U(North) \\
\hline CUI(South) & 1,00 & $* * *$ & --- & --- & --- & --- & -- & --- \\
CUI(North) & 0,62 & 1,00 & --- & --- & $* * *$ & $* * *$ & --- & --- \\
NAO & $-0,09$ & $-0,03$ & 1,00 & $* * *$ & --- & --- & --- & --- \\
SLP & 0,07 & 0,17 & 0,87 & 1,00 & --- & --- & --- & --- \\
V(South) & $-0,26$ & $-0,78$ & 0,13 & $-0,03$ & 1,00 & $* * *$ & --- & --- \\
V(North) & $-0,32$ & $-0,82$ & 0,16 & 0,01 & 0,96 & 1,00 & --- & --- \\
U(South) & 0,11 & 0,18 & $-0,40$ & $-0,24$ & 0,02 & $-0,05$ & 1,00 & $* * *$ \\
U(North) & 0,16 & 0,32 & $-0,35$ & $-0,17$ & $-0,29$ & $-0,24$ & 0,72 & 1,00 \\
\hline
\end{tabular}

Several statistically significant correlations $(p<0.05)$ are found between the seasonal averages of the upwelling index (CUI $\left.{ }_{\mathrm{SST}}\right)$ and the corresponding CCMP wind components (U, $\mathrm{V})$. The Northern upwelling index (CUI $\mathrm{Corth})$ is significant for all three seasons, between 0.48 in summer and between 0.73 and 0.83 in autumn and winter, with moderate differences between the wind sub-region, while the Southern upwelling index (CUIsouth) is significantly correlated with the Meridian wind in summer only. Not surprisingly, the highest correlations are found for the northern zone with the Northern meridian wind (-0.83 in Autumn and -0.82 in winter) and for the southern zone (respectively-0.73 and -0.78). Only one significant relationship is observed between the SLP and the upwelling index, for the central zone in summer (0.43).

Likewise, the North Atlantic Oscillation could influence the coastal upwelling intensity off the North-west African region because of its influence on the Azores high. During winter, both NAO and SLP are correlated with the zonal and meridian wind components (U, V). However, CUISsT is negatively correlated with NAO and SLP (except in summer where SLP is correlated with CUISST in the northern zone). Furthermore, the NAO and the SLP are significantly correlated with the two wind components $\mathrm{U}$ and $\mathrm{V}$ for the North and for the South during the Autumn season. This result confirms that the local wind is the main driver of the coastal upwelling as a result of large-scale atmospheric forcing, with a direct influence in the coastal domain. The autumn season is therefore critical for the seasonality of upwelling.

Seasonnal correlations did not reveal any relation between the upwelling index and NAO. This lack of correlation means that the influence of the NAO on the coastal upwelling is spatially too indirect to have a visible action on the coastal domain.

However, monthly time series explored with a cross correlation function (CCF) is a step forward to explore basin-wide processes and their mechanisms.

\subsection{Cross-correlation function (CCF)}

The autocorrelation analysis on the monthly averages time series makes it possible to account for existing time lags in the time series in order to explore underlying mechanisms.

The Fig. 10 shows the cross-correlation function (CCF) for time lags varying from -20 to 20 months between the CUISST variable and SLP /NAO synoptic variables for both sub-regions.

At the northern sub-region, the correlation between CUISST and SLP is significant at positive lags of 0 and 1 month (Fig.10a), but the correlation is more significant lags between -2 and -3 
months. Contrariwise, the correlation between the NAO and the CUISsT (Fig.10b) has instantaneous or near-instantaneous lag of +1 month. So, it can happen; NAO dynamics can be obvious after the upwelling dynamics. Moreover, in this particular case this correlation is likely to be indicative of the effects of the NAO on CUI SST change at decadal to multi-decadal timescales.

At the southern zone (Figure 10c and d), the correlation between CUISST and SLP is significant at-3 months lag while no correlation can be reported between the NAO and the CUIsst in this area (Figure 10d).

A significant correlation coefficient at a negative time lag of 3 months indicates thatSLP can be used to predict the upwelling phenomenon three months in advance. Also, a positive correlation with a one-month lag obtained between the CUISST and the NAO for the central zone can partially explain that the link of NAO with CUISsT becomes obvious after the dynamics of upwelling.


Figure 10 Estimated cross correlations ( $a, c)$ between SLP and CUIsst (b, d) between NAO and CUIssT at different time lags related to the northern (area1) (a, b) and southern (area2) (c, d) of morocco. The two horizontal bands represent the limits of significance at $5 \%$ level.

As we know that the NAO index is defined by measurement of the pressure difference between the Icelandic Low and Azores High at two fixed locations, Lisbon, Portugal and Stykkisholmur, Iceland. However, it is known that these two pressure systems have extended structures that migrate considerably and their motions are not entirely coupled. As such, a better estimate of influence of atmospheric pressure fluctuations on the climate variability in this studied region can be achieved through a more quantitative assessment of the fluctuations in the pressure.

\subsection{Spectral analysis}

To complete our analysis, the Fig. 11 presents a spectral test of the temporal variability of the thermal upwelling index. The spectrum is estimated from a smoothed Periodogram (Venables and Ripley 2002) that uses the Fast Fourier Transform whose purpose is to detect patterns of periodic oscillations that can be observed along of the time series. In fact, the estimated spectrum decomposes the motion of the series into various sinusoids waves of different frequencies and displays the relative strength of each oscillation. Low frequencies measure the contribution of long-term oscillations, while high frequencies measure the contribution of shortterm oscillations. Periodograms suggested spectrum at frequency (1/years) of 0.16 in summer 
and winter and to 0.20 in transitional season (Fig.11), suggesting a potential low-frequency oscillation about $5-6$ years. The spectrum was higher in transitional season than in summer and winter.

The existence of the low-frequency ( 5 to 6 years oscillation) signal in the CUISST time series, and the fact that these signal is significantly correlated with the SLP and with alongshore wind stress, strongly suggest that its mainly driven by non local prevailing (both in time and space) previous atmospheric and oceanic conditions.

Indeed, the NAO index results from the differential pressure between the Azores High and Icelandic low, any fluctuations can potentially modify the intensity of the upwelling favorable wind and hence inter-annual changes in the intensity of the upwelling. Moreover, the Atlantic and the Pacific Ocean are coupled via the atmospheric circulation (Hurrell 1996). The spectacular Pacific El Niño-Southern Oscillation (ENSO) occurring fluctuation with periods of 3 to 7years, can potentially acts on Atlantic region via teleconnection (Behrenfeld et al., 2001; Zeeberg et al., 2008) and changes the atmospheric circulation patterns (May and Bengtsson, 1996).

As pointed out by Fischer et al. 2016, that the relationship between NAO and EL Niño might displays during winter an opposite effect on the North-west African wind fields, and consequently on reducing upwelling intensity. A positive phase of the NAO is associated with anomalous high pressure in the Azores high region and stronger upwelling-favorable northeasterly winds along the NW African coast. On the contrary, El Niño event outcomes with a weakening of the trade wind in the study area as its was the case during the anomalous period (1995-1997) of our studied time series (Fisher et al. 2016).
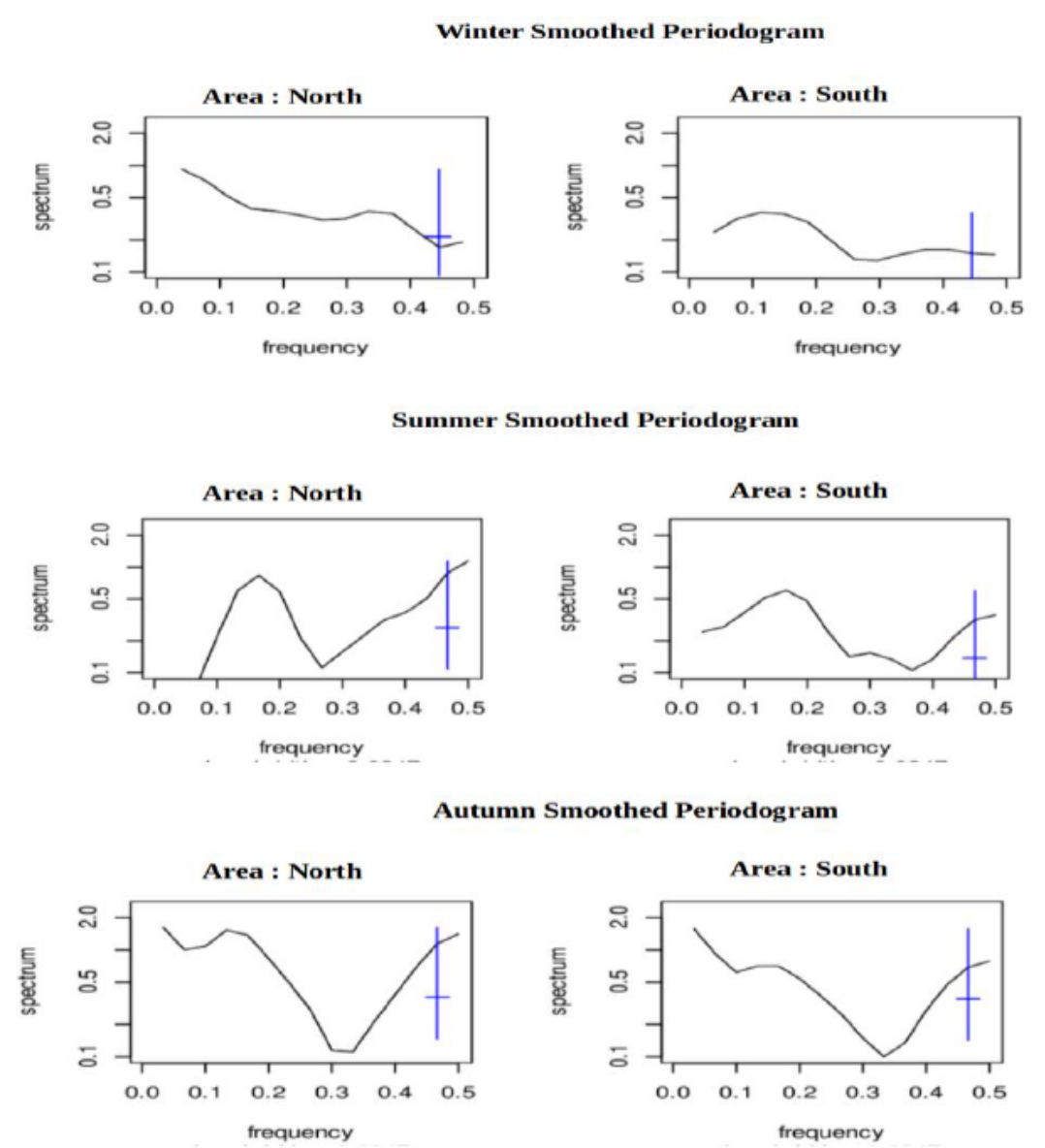

Figure 11 Periodograms suggested spectrum at frequency (1/year) of 0.16 to 0.20 in winter, summer and transitional autumn season 
Aïssa Benazzouz, Khalid EL Khalidi, Hassan Mabchour, Khalid EL Had, Soumia Mordane, Bendahhou Zourarah, Naoki Tojo and Hervé Demarcq

\section{CONCLUSION}

The analysis carried out tend to explore the influence of the synoptic atmospheric patterns on the coastal upwelling. To give a physical interpretation of the correlation analysis, four methods were used: (1) Time Series Analysis, (2) Extreme Event Analysis (3) SLP/Wind Composite Analyzes and (4) Cross Correlation Function.

Nevertheless, the correlation between the CUIssT and the atmospheric indices is carried out in order to consider the ocean-atmosphere interaction.

It is clear from that, the atmospheric conditions in the coastal domain and the intensity of the coastal upwelling are related to the intensity and location of the Azores High.

The NAO shows a strong inter-annual and intra-annual variability. However, several studies have shown that changes in NAO trends have a delayed effect on aquatic ecosystems due to ecosystem inertia (Borges et al., 2003). The synoptic events observed prior to the response of the upwelling intensity at least one to three months evidencing the causal relationship between atmospheric forcing and thermal ocean response. This physical relationship finds its origin in the center of the high atmospheric pressures at the Azores which condition the distribution of the upwelling-favorable wind field. The seasons swaying and alternation are accompanied by the migration of the high pressures core and thus the change of the wind regimes.

The exceptionally low upwelling index observed during the winter of the 1995-1997 period in the northern area of Morocco is related to the exceptional relaxation of the trade winds and the intensity of the atmospheric pressure at the Azores system which was the lowest during the study period ( $<1018$ mbar). In addition, the presence of a very negative NAO phase (NAO-) during the winter of 1995, 1996 and 1997 may explain the Autumn in upwelling activity during this strong anomalous period. Given the complexity of the relationship between the physical environment and the meteorological dynamic processes, potentially observable associations are expected to be noisy with multiple dimensions from local to large-scale processes.

The observed anomaly is occurred after a phenomenal Pacific EL Nino during 1997 and 1998 (Benazzouz et al., 2014) suggesting that the zonal wind playing a leading role linking the Pacific and Atlantic Ocean basins through the atmospheric Walker circulation and associated oceanic processes (Wang et al. 2009).

The complex behavior is well reflected by significantly weak seasonal correlations between NAO and CUISST for the two Moroccan areas (Central and South). A systematic link between the NAO and the upwelling favorable-wind is far to be linearly established. Not surprisingly, the hydrodynamical processes on the Moroccan area set by the physical wind forcing and CUISsT response seem to be modulated by the SLP rather than the NAO which plays potentially a very prominent role in the observed extreme events of the upwelling process, rather than the long-term variability of upwelling.

Spectral analysis reveals a spectrum at frequencies of $1 / 0.16$ years to $1 / 0.20$ years in summer and autumn suggesting a potential oscillation of 5 to 6 years. The spectrum is higher in autumn than in summer.

Temporal dynamics of the upwelling index were fairly explained by the global and regional meteorological variables represented by Azores High which provide an explanation of the two upwelling controlling scenarios (strong and weak). Understandings the environmental scenarios with dominant regional patterns will allow the researchers to explain and predict the observed dynamics as well as to obtain the practical environmental index for the further modeling. 
Synoptic atmospheric patterns controlling the North-West African oceanographic variability

\section{REFERENCES}

[1] Atlas R, Hoffman RN, Ardizzone J, Leidner SM, Jusem JC (2009) Development of a new crosscalibrated, multi-platform (CCMP) ocean surface wind product. In: Proceedings of AMS 13th Conference on Integrated Observing and Assimilation Systems for Atmosphere, Oceans, and Land Surface (IOAS-AOLS).

[2] Behrenfeld, M. J., Randerson, J. T., McClain, C. R., Feldman, G. C.,Los, S. O., Tucker, C. J., Falkowski, P., Field, C. B., Frouin, R.,Esaias, W. E., Kolber, D. D., and Pollack, N. H.: Biospheric pri-mary production during an ENSO transition, Science, 291, 2594-2597, 2001.

[3] Benazzouz A, Mordane S, Orbi A, Chagdali M, Hilmi K, Atillah A, Pelegrí J L and Demarcq H (2014a). An improved coastal upwelling index from sea surface temperature using satellite based approach - The case of the Canary Current upwelling system. Continental Shelf Research, Vol. 81, pp. 38-54. doi:10.1016/j.csr.2014.03.012

[4] Benazzouz A, Pelegrí J L, Demarcq H, Machín F, Mason E, Orbi A, PeñaIzquierdo J and Soumia M (2014b) On the temporal memory of coastal upwelling off NW Africa. Journal of Geophysical Research: Oceans, Vol. 119, pp. 6356-6380. doi:10.1002/2013JC009559

[5] Benazzouz A, Demarcq H and González Nuevo G (2015) Recent changes and trends of the upwelling intensity in the Canary Current Large Marine Ecosystem. In: Valdés, L. and Déniz González, I. (eds). Oceanographic and biological features in the Canary Current Large Marine Ecosystem. IOC-UNESCO, Paris. IOC Technical Series, No. 115, pp. 321-330

[6] Benedict JJ, Lee S, FeldsteinS B (2004) Synoptic view of the North Atlantic Oscillation. J. Atmos. Sci., 61, 121-144

[7] Borges MF, Santos AMP, Crato N, Mendes H, and B. Mota B (2003) Sardine regime shifts off Portugal: a time series analysis of catches and wind conditions. SCI MAR, 67 (suppl.1): 235244

[8] Brander K, Mohn R (2004). Effect of the North Atlantic Oscillation on recruitment of Atlantic cod (Gadus morhua). Canadian Journal of Fisheries and Aquatic Sciences 61: 15581564

[9] Cayan D, Latent R (1992) Sensible heat flux anomalies over the northern oceans: The connection to monthly atmospheric circulation, J. Climate, 5, 354-369

[10] Demarcq H, Faure V (2000) Coastal upwelling and associated retention indices derived from satellite SST. Apllication to Octopus vulgaris recruitement. Oceanol. Acta 4, 11231-11246

[11] Fischer G, Romero O,, Merkel U, Donner B, Iversen M, Nowald N, Ratmeyer V, Ruhland G, Klann M, Wefer G (2016) Deep ocean mass fluxes in the coastal upwelling off Mauritania from1988 to 2012: variability on seasonal to decadal timescales Biogeosciences, 13, 30713090, doi:10.5194/bg-13-3071-2016

[12] Feldstein SB (2003) The dynamics of NAO teleconnection pattern growth and decay. Q. J. R. Meteorol. Soc. 129: 901-924

[13] Franzke C, Lee S, Feldstein SB (2004) Is the North Atlantic Oscillation a breaking wave? J.Atmos. Sci. 61: 145-160

[14] Hagen E, Feistel R, Agenbag JJ, Ohde T (2001) Seasonal and interannual changes in Intense Benguela Upwelling (1982-1999) Oceanol. Acta., 24, pp. 557-568

[15] Ginzburg AI, Kostianoy AG, Sheremet NA (2008b) Interannual variability of sea surface temperature in the Black, Marmara and Aegean seas and its response to global atmospheric forcing. 2nd Biannual and Black Sea SCENE EC Project Joint Conference. Climate Change in the Black Sea-Hypothesis, Observations, Trends Scenarios and Mitigation Strategy for the Ecosystem, 6-9 October 2008, Sophia, Bulgaria, Paper Abstracts

[16] Helmke P (2003) Remote sensing of the Northwest African upwelling and its production dynamics. Tesis doctoral. Universität Bremen, Alemania. 165 pp. ICES WGSPEC REPORT

[17] Hurrell JW, Kushnir Y, Ottersen G (2003) An overview of the North Atlantic oscillation. The North Atlantic Oscillation: Climatic Significance and Environmental Impact, Geophys. Monogr., Vol. 134, Amer. Geophys. Union, 1-35, doi:10.1029/134GM01 
Aïssa Benazzouz, Khalid EL Khalidi, Hassan Mabchour, Khalid EL Had, Soumia Mordane, Bendahhou Zourarah, Naoki Tojo and Hervé Demarcq

[18] Hurrell JW (1995) Decadal trends in the North Atlantic Oscillation: Regional temperature and precipitation. Science, $269,676-679$

[19] Hurrell JW (1996) Influence of variations in extratropical wintertime teleconnections on Northern Hemisphere temperature. Geophysical Research Letters 23: 665 - 668.

[20] Kalnay E (1996) The NCEP/NCAR 40-Year Reanalysis Project. Bull. Amer. Meteor. Soc., 77, 437-471, doi:10.1175/1520-0477(1996)077,0437:TNYRP.2.0.CO;2

[21] Kazmin AS, Zatsepin AG (2007) Longterm variability of surface temperature in the Black Sea, and its connection with the largescale atmospheric forcing. Journal of Marine Systems 68(1-2): 293-293, DOI: 10.1016/j.jmarsys.2007.01.002

[22] Lathurilère C, Echevin V, Lévy M (2008) Seasonal and intraseasonal surface chlorophyll-a variability along the northwest African coast. J. Geophys. Res. 113, C05007, http://dx.doi.org/10.1029/2007JC004433

[23] Luo D, Lupo AR, Wan H (2007) Dynamics of eddy-driven low-frequency dipole modes. Part I: A simple model of North Atlantic Oscillations. J. Atmos. Sci. 64: 3-28

[24] Luo D, Gong T, Diao Y (2008a) Dynamics of eddy-driven low-frequency dipolemodes.PartIV:Planetaryands ynopticwave-breakingprocesses during the NAO life cycle. J. Atmos. Sci. 65: 737-765

[25] Luo D, Gong T, Zhong L (2008b) Dynamical relationship between the phase of North Atlantic Oscillations and the meridional excursion of a preexisting jet. An analytical study. J. Atmos. Sci. 65: $1838-1858$

[26] Machu E, Ettahiri O, Kifani S, Benazzouz A, Makaoui A, Demarcq H (2009) Environmental control of the recruitment of sardines (Sardina pilchardus) over the western Saharan shelf between 1995 and 2002: a coupled physical-biogeochemical modelling experiment. Fish. Oceanogr. 18 (5), 287-300

[27] MacKenzie BR, Köster FW (2004) Fish production and climate: Sprat in the Baltic Sea. Ecology 85: 784-794

[28] May W, Bengtsson L (1996) On the impact of theEl Niño/ SouthernOscillation phenomenon on the atmospheric circulation in thenorthern hemisphere extratropics. Max-Planck-Institut für Meteo-rologie Rep. No. 224, 1-61.

[29] Mittelstaedt E (1983) The upwelling area off Africa - a description of phenomena related to coastal upwelling. Prog. Oceanogr. 12, 307-331

[30] Mittelstaedt E (1991) The ocean boundary along the northwest African coast: circulation and oceanographic properties at the sea surface. Prog. Oceanogr. 26,307-355

[31] Thiel M, Macaya EC, Acuna E, Arntz WE, Bastias H, Brokordt K, Camus PA, Castilla JC, Castro LR, Cortes M, Dumont CP, Escribano R, Fernandez M, Gajardo JA, Gaymer CF, Gomez I, Gonzalez AE, Gonzalez HE, Haye PA, Illanes JE, Iriarte JL, Lancellotti DL, Luna-Jorquerai G, Luxoroi C, Manriquez PH, Marin V, Munoz P, Navarrete SA, PerezE, Poulin E, Sellanes J, Sepulveda HH, Stotz W, Tala F, Thomas A, Vargas CA, Vasquez JA, Vega JMA (2007) The humboldt current system of northern and central Chile.Oceanogr. Mar. Biol., 45 (2007), pp. 195-344

[32] Oguz T, Tugrul S, Kideys AE, Ediger V, Kubilay N (2005) Physical and biogeochemical characteristics of the Black Sea. The Sea 14:(Chapter 33): 1331-1369.

[33] Ottersen G, Planque B, Belgrano A, Post E, Reid PC, Stenseth NC (2001) Ecological effects of the North Atlantic Oscillation. Oecologia 128,1-14

[34] Pedlosky J (1978) A nonlinear model of onset of coastal upwelling, J. Phys. Oceanogr., 8, 178187

[35] Pérez-Brunius P, Lopez M, Pares-Sierra A, Pineda J (2007) Comparison of upwelling indices off Baja California derived from three dif ferent wind data sources CalCOFI Rep., 48, 204-214

[36] Planque B, Fredou T (1999) Temperature and the recruitment of Atlantic cod (Gadus morhua). - Canadian Journal of Fisheries and Aquatic Sciences 56: 2069-2077 
[37] Davis RE, Hayden B, Gay D, Philips W, Jones A, (1997) The North Atlantic Subtropical Anticyclone, J. Climate, 10,728-744

[38] Rogers JC (1997) North Atlantic storm track variability and its association to the North Atlantic Oscillation and climate variability of Northern Europe, J. Climate 10, 1635-1645

[39] Santos F, Gomez Gesteira M, deCastro M, Alvarez I (2011) Differences in coastal and oceanic SST trends due to the strengthening of coastal upwelling along the Benguela Current system. Cont. Shelf Res., 79-86, http://dx.doi.org/10.1016/j.csr

[40] Speth P, Detlefsen H, Sierts HW (1978) Meteorological influence on upwelling off Northwest Africa. Dtsch. Hydrogr. Z. 31, 95-104

[41] Speth P, Köhne A (1983) The relationship between sea surface temperatures and wind off Northwest Africa and Portugal. Oceanogr, Tropical 18, 69-80

[42] Van Camp L, Nykjaer L, Mittelstaedt E, Schlittenhardt P (1991) Upwelling and boundary circulation off northwest Africa as depicted by infrared and visible satellite observations. Prog. Oceanogr. 26, 357-402

[43] Wallace JM, Smith C, Jiang Q (1990) Spatial patterns of atmospheric- ocean interaction in the northern winter. J. Climate, 3, 990-998

[44] Venables WN, Ripley BD (2002) Modern Applied Statistics with S. 4th edition. SpringerVerlag, New York

[45] Visbeck M, Cullen H, Krahmann G, Naik NH (1998) An ocean models response to North Atlantic Oscillation-like wind forcing. Geophysical Research Letters, 25, 4521-4524

[46] Walker GT, Bliss EW (1932) World weather V. Mem. Roy. Meteor. Soc., 4 (36), 53-84

[47] Walker G (1924) Correlations in seasonal variations of weather IX. Mem. Indian Meteorol Dep., 24, pp. 275-332

[48] Wang C, Kucharski F, Barimalala R, Bracco A (2009) Teleconnections of the tropical Atlantic to the tropical Indian and Pacific Oceans: a review of recent findings. Meteorol Z 18,445-454

[49] Wooster WS, Bakun A, McLain D (1976) The seasonal upwelling cycle along the eastern boundary of the North Atlantic. J. Mar. Res. 34 (2), 131-141

[50] Zeeberg J, Corten A, Tjoe-Awie P, Coca J, Hamady B (2008) Climate modulates the effects of Sardinella aurita fisheries of Northwest Africa. Fish. Res., (89), 65-75.

[51] Zorita E, Kharin V, Von Storch H (1992) The atmospheric circulation and sea-surface temperature in the North Atlantic area in winter: Their interaction and relevance for Iberian precipitation. J. Climate, 5, 1097-1108 